\title{
Force-in-Chain Study of Chain-Electric Hoist with Periodical Variable Angular Rotational Velocity of Chain-Wheel
}

\author{
Ivan Balashev, Silviu Macuta \\ Technical University of Gabrovo, Bulgaria, Dunarea de jos University of Galati, Romania
}

\begin{abstract}
Lifting mechanism of chain electric hoist with periodical variable angular velocity of chain-wheel has been studied in this paper. The non-uniform movement of chain is considerably decreased and from where the dynamic load is also decreased. The experimental studies of the lifting mechanism have been carried out at different operation modes. The results from these studies have been graphically presented and conclusions have been done.
\end{abstract}

Key words: chain electric hoist, experimental studies, force-in-chain.

\section{INTRODUCTION}

Lifting mechanism of chain electric hoist with periodical variable angular velocity of chain-wheel has been developed and studied. This leads to compensation in large degree of the non-uniformity of the load movement and also the dynamics is improved.

\section{THEORETICAL AND EXPERIMENTAL STUDIES}

The mechanical diagram of lifting mechanism of chain electric hoist with periodical variable angular velocity of chain-wheel is shown in Figure 1 [1, 2]. It is driven by asynchronous electric motor with conic rotor and built-in brake connected with a planetary gear 2 which is contacted to the other one with periodical variable gear ratio from $2 \mathrm{KH}-\mathrm{KA}$ type. It is consisted of central gears 3 and 4 in which planet gears 5 put on a carrier 6 are engaged.

The carrier is put on the output shaft of the gear where the chain-wheel 8 is mounted. The gear 10 , engaged with gear 11 and bearing supported on the fixed axis 12 , is put on the driving shaft 9 . An elbow 13 , entering in a radial canal of the strip 14 fixed on gear 4 with internal teeth, is mounted on one side of the gear 11.

During the rotation of the driving shaft 9 with constant angular velocity $\omega_{9}$, one basic rotation motion of the output shaft 7 with angular velocity $\omega_{7,0}$ is received. The second reciprocal-rotation motion with angular velocity $\omega_{\overline{7}}$ is added to the first one. The second motion is formed by closing kinematic chain (link gear) [1] which is consists of gears 10 and 11, eccentric 13 and strip with canal 14.

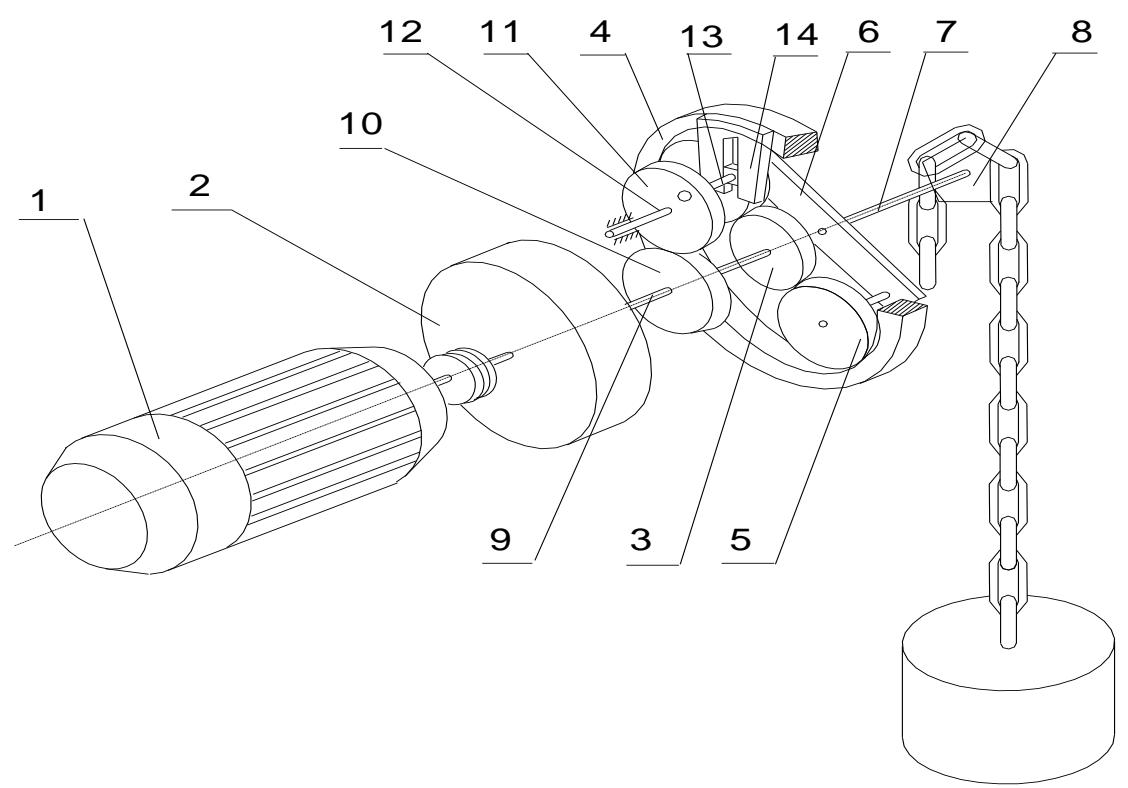

Fig 1. Scheme of lifting mechanism 
The periodical variable angular velocity $\omega_{\mathrm{kz}}$ of the chain-wheel is determined as follows [1]:

$$
\omega_{k z}=\omega_{7,0}+\omega_{7}=\frac{1+\frac{a \cdot e \cdot \cos \left(\varphi_{9} / i_{o}\right)-e^{2}}{e^{2}+a^{2}-2 \cdot a \cdot e \cdot \cos \left(\varphi_{9} / i_{o}\right)} \cdot \frac{z}{i_{o}}}{1-z} \cdot \omega_{9}
$$

where $\varphi_{9}$ is the rotation angle of shaft 9 ; $a$ and $\mathrm{i}_{0}=\mathrm{z}_{11} / \mathrm{z}_{10}$ are center distance and gear ratio of the closing gear with gears 10 and 11 respectively;

$e$ is an eccentricity of the elbow 13;

$\mathrm{z}=-\mathrm{Z}_{4} / \mathrm{z}_{3}$ is an parameter of the planetary

gear.

The variation of angular velocity $\omega \mathrm{kz}$ of rotation of the chain-wheel is shown in Figure 2. It is determined at different values of the eccentricity e according to angle $\omega 9$ of driving shaft 9 . The other parameters are accepted as follows: $z=-4$; number of teeth of the chain-wheel $\mathrm{zk}=5$ and $\mathrm{a}=67.5 \mathrm{~mm}$.

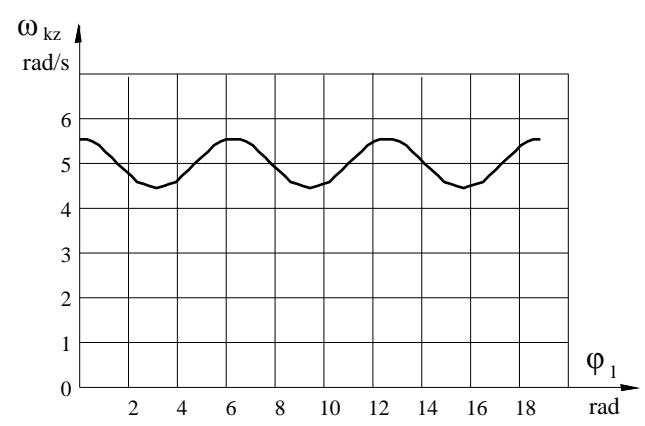

Fig 2. Theoretical determinate variation of the angular velocity

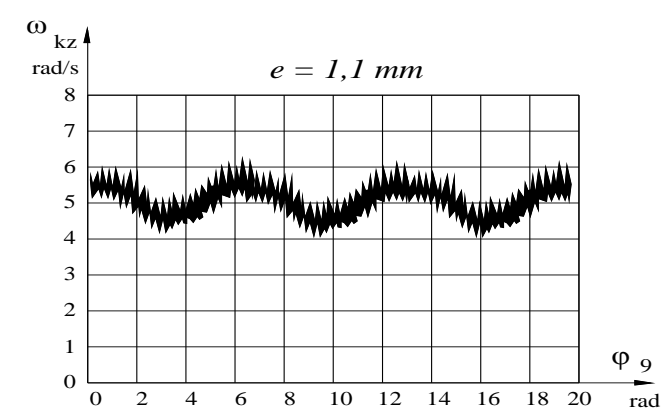

Fig 3. Experimental determinate variation of the angular velocity

The experimental studies of laboratory model of chain electric hoist with periodical variable angular velocity of chain-wheel have been carried out. This model has been developed in Technical University of Gabrovo. The following records have been made for the variation of the angular velocity $\omega_{\mathrm{kz}}$ of rotation of the chain-wheel (Figure 3), for the variation of forcein-chain at rotation of the chain-wheel with periodical variable angular velocity (Figure 4) as well as for the variation of force-in-chain at rotation of the chainwheel with constant angular velocity (Figure 5) at condition of load lifting.
Force-in-chain at lifting from the ground with rotation of the chain-wheel

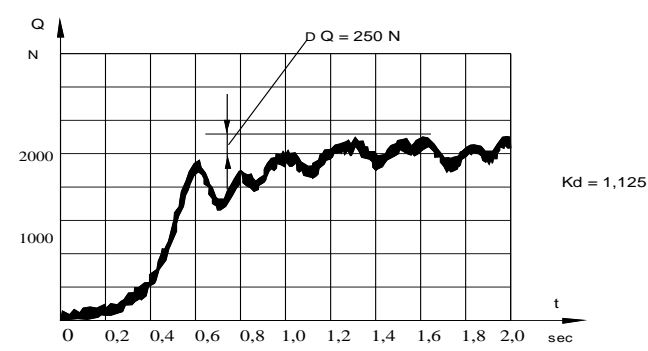

Fig 4. With periodical variable angular velocity

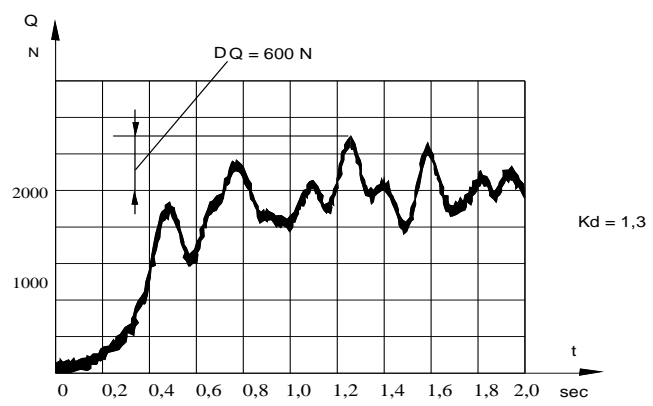

Fig 5. With constant angular velocity

Experimental studies at the other operation modes of the chain electric hoist with "polygon effect" compensation of the chain drive have been carried out. The results have been compared with these ones of the existing constructions of chain electric hoist with rotation of the chain-wheel with constant angular velocity.

Oscillograms of variance of the force-in-chain at condition - stopping at the end of load lifting are shown in Figure 6 and Figure 7. Oscillograms of variance of the force-in-chain at condition - lifting of suspended load are shown in Figure 8 and Figure 9.

Force-in-chain at stopping at the end of load lifting with rotation of the chain-wheel

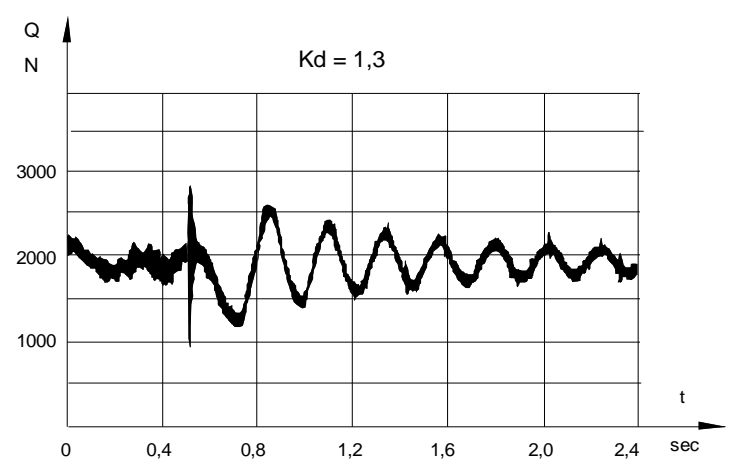

Fig 6 With periodical variable angular velocity 


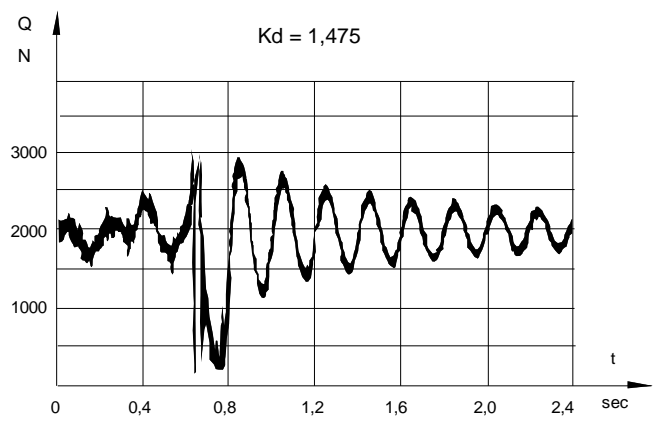

Fig 7 With constant angular velocity

Force-in-chain at lifting of suspended load with rotation of the chain-wheel

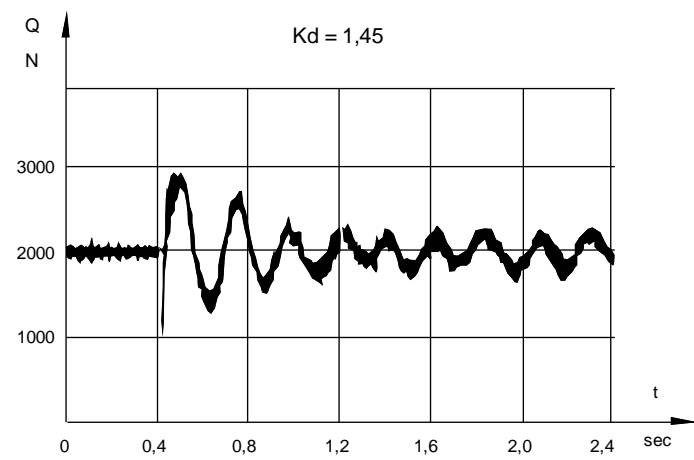

Fig 8 With periodical variable angular velocity

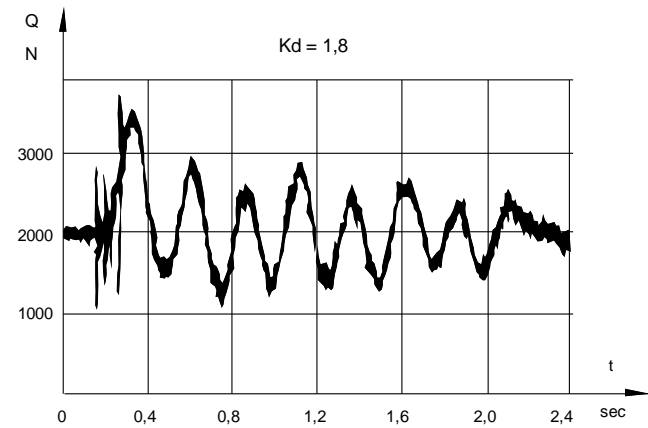

Fig 9. With constant angular velocity

Oscillograms of variance of the force-in-chain at condition - lowering of suspended load are shown in Figure 10 and Figure 11. Oscillograms of variance of the force-in-chain at condition - stopping of suspended load are shown in Figure 12 and Figure 13.

The coefficients for dynamism have been determined for each operation mode of two lifting mechanisms of chain electric hoists. They are given in the tables and also are determined by means of the following relationship:

$$
k_{d}=\frac{Q+\Delta Q}{Q}
$$

Force-in-chain at lowering of suspended load with rotation of the chain-wheel

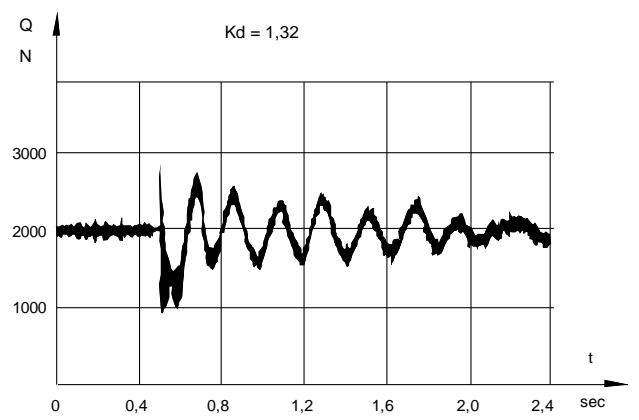

Fig 10. With periodical variable angular velocity

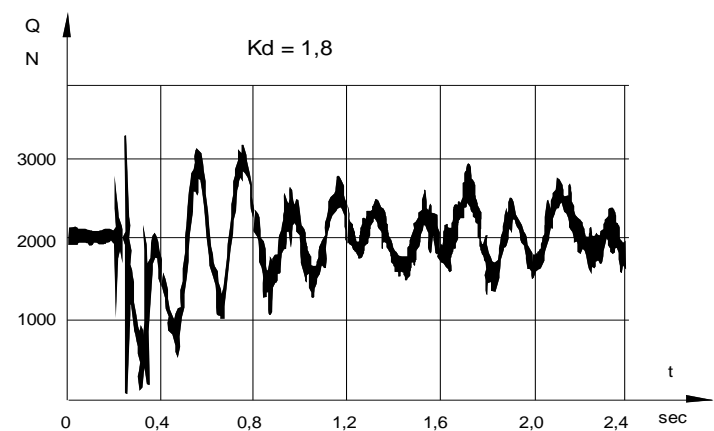

Fig 11. With constant angular velocity

Force-in-chain at stopping of suspended load with rotation of the chain-wheel

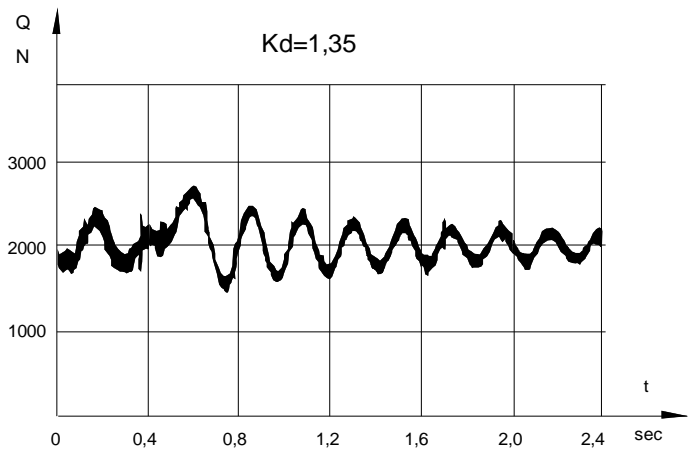

Fig 12 . With periodical variable angular velocity

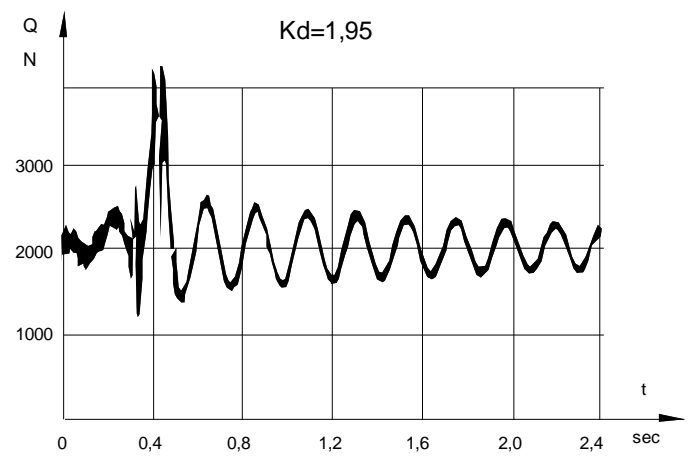

Fig 13. With constant angular velocity 


\section{CONCLUSIONS}

The following conclusions have been drawn by means of the carried-out theoretical and experimental studies of lifting mechanism of chain electric hoist which are connected with an application of the planetary gear $2 \mathrm{KH}-\mathrm{KA}$ type with periodical variable gear ratio:

- An original construction of lifting mechanism of chain electric hoist with an application of the planetary gear $2 \mathrm{KH}-\mathrm{KA}$ type with periodical variable gear ratio has been developed. The "polygon effect" of the chain drive is compensated at this design.

- The non-uniform movement of the chain (load) is decreased at the suggested construction of chain electric hoist because of the compensation of the "polygon effect" of chain drive as well as this one of the dynamic loads.
- The coefficient of dynamism $\mathrm{k}_{\mathrm{d}}$ at the suggested construction is decreased with $15,5 \%$ at the condition of load lifting from the ground during the carried-out dynamic experimental studies of lifting mechanism of chain electric hoist with an application of the planetary gear $2 \mathrm{KH}-\mathrm{KA}$ type with periodical variable gear ratio.

\section{REFERENCES}

[1] Балашев, И. Л., Планетарные передачи с циклическим переменым передаточным отношение, International Congress Gear Transmissions, vol. II, 1995.

[2] Balashev, I. L., L. Stoyanov, Planetary gear, Inventor's certificate No 51647, MPK F 11 H3 / 44,1996 . 